All of the submissions in this issue of $\mathrm{Art}$ Libraries Journal attest to our desire to understand our culture, to understand ourselves as social beings. This is manifested in one way by the compulsion to collect material and information and, further, to order and interpret it in some meaningful way. And this impulse is not exclusively a collective or institutional one. Virtually all public collections rely on private interests, such as those represented by the Joseph Laurence photo album in the Centre for Newfoundland Studies collection, or Donald Cameron Mackay's dictionary of Nova Scotian artists. Mackay's manuscript as well as Scott Robson's ongoing editorial work on it, reflect a personal as well as a professional interest, and both have occurred extra-institutionally. In any case, it is important to recognize not only that these activities reflect an awareness of, and evidence that, cultural activity has taken place in Atlantic Canada - be it mapping, art making, writing, publishing, journal writing and even speech - but that collecting and interpreting are cultural activities in themselves.

This point is vividly presented in John Murchie's essay in which he notes that institutions can and do assign value and define visual identities - for a country, a region, a people. Murchie's call for a regional role and responsibility in understanding Atlantic Canadian culture specifically is sharpened by his observation that, in its absence, others (in this case the National Gallery of Canada) will take the lacuna and develop a picture by identifying what they discover as having value within a particular frame of reference.

By the same token, that there is an awareness nationally of a folk art sensibility in Atlantic Canada is, as Susan Foshay notes in her bibliographic essay, due to the substantial literature and curatorial energy devoted to the subject by visual arts institutions and museums in the region. The important Bibliography of Newfoundland and the Newfoundland periodical article bibliography, both prepared by the Centre for Newfoundland Studies, will and must not only dramatically improve the extent of information researchers will find, but also be a factor in determining their perceptions, as will the New Brunswick illustration index at the Legislative Library. And, as thoughtfully documented in Ilga Leja's article, the development at the Nova Scotia
College of Art and Design of a major art library, international in scope, critically alters what is culturally accessible and knowable.

We are fortunate to have an artwork included in this issue, which, for me, formally and conceptually touches on these issues. Michael Fernandes's text of one long run-on sentence is simply a list of things (hammers, socks, receipts, pencils, his car) and information (the colour of his house paint) which he has lost. This litany of woes is contrasted visually with five pages of photographs of catalogued, neatly shelved books; the epitome of order. As I understand it, the work makes a case for the value of retrieval systems which identify and code, so that we can find what we are looking for. (It is interesting that Fernandes's text is presented unbound in this volume, representing the real threat of loss.) But while the artist has lost only a sock or a pencil, it is the reader, struggling with a text devoid of punctuation, who is truly in the dark. We read without any clues as to where one thought stops and another begins. In Fernandes's run-on nightmare are we to understand that his socks were lost down at the mall and that he missed his son's birthday after three years of not doing his taxes? By eliminating one of the important ordering principles of reading, Fernandes not only makes us aware of our dependence on it for meaning, but also exposes it as a cultural determinant of meaning.

The activities described in this issue are significant, then, because they are more than seemingly pure or routine acts of amassing and codifying material and information. The commitment to develop collections, the choices of what to collect and what to ignore, of what to describe and how to classify, are all ways of assigning value and meaning, and as such they both define the culture of Atlantic Canada and are an integral part of it.

\section{Gemey Kelly,}

Director,

Owens Art Gallery,

Sackville,

New Brunswick

\section{Deputy Editor's note:}

Michael Fernandes whose site-specific piece appears on pages 24-28 (with a single loose-leaf sheet) is an artist from East-

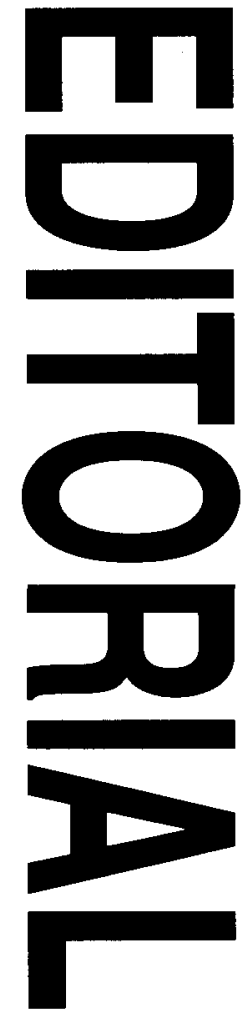



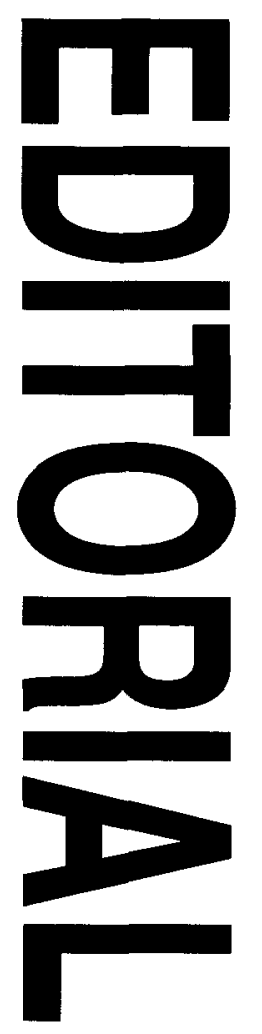

Dover, Nova Scotia. A recent article by Stephen Horne entitled 'Michael Fernandes: the everyday escapes' appeared in Parachute 87 (July, August, September 1997): p.22-27. Photographs: David Green.

\section{Editor's note:}

The material on Atlantic Canada which makes up the bulk of this issue of $A r t$ Libraries Journal has been gathered together and edited by our Deputy Editor, Peter Trepanier. I would like to express my personal gratitude to him for this and other special compilations and for his splendid support over several years - support which will now be extended to my successor. 